\title{
SEGMENTAL DAN SUPRA SEGMENTAL DALAM KIDUNG MALAT COWAK DI DESA PADANGBULIA
}

\author{
Oleh:I Gusti Made Swastya Dharma Pradnyan
}

\begin{abstract}
Malat Cowak a traditional literary works shaped hymn often sing Padangbulia society. This kidung serves as a companion religious ceremonie's such as, pitra yadnya and manusia yadnya. But when song, chants significant they can only be interpreted by readers based on the dictionary meaning only. As an active reader, a work of literature, especially the kidung, various kinds of theories and methods in the process of interpretation of the meaning. One way is to analyze the sound system that ties each end of words in one verse. Study of the sound system in linguistics is based on the study of phonology. Science that examines the sound system can be done with two analysis: analysis of segmental and suprasegmental.
\end{abstract}

Keywords: Segmental, Supra Segmental, Song Malat Cowak.

\begin{abstract}
Abstrak
Malat Cowak merupakan karya sastra tradisional berbentuk kidung yang sering dinyanyikan masyarakat Padangbulia.Kidung ini berfungsi sebagai pengiring upacara keagamaan diantaranya, pitra yadnya dan manusia yadnya.Namun pada saat dinyanyikan, makna kidung tersebut hanya dapat diinterpretasikan oleh pembaca berdasarkan arti kamus saja. Sebagai pembaca aktif, sebuah karya sastra khususnya kidung, diperlukan berbagai macam teori dan metode dalam proses interpretasi makna. Salah satunya adalah dengan menganalisis sistem bunyi yang mengikat masing-masing akhir kata dalam satu bait.Telaah sistem bunyi dalam ilmu linguistik dilakukan berdasarkan kajian fonologi.Ilmu yang mengkaji sistem bunyi tersebut dapat dilakukan dengan dua analisis yaitu analisis segmental dan suprasegmental.
\end{abstract}

Kata Kunci: Segmental, Supra Segmental, Kidung Malat Cowak.

\section{PENDAHULUAN}

Sistem bunyi yang dihasilkan oleh alat ucap disepakati sebagai bahasa.Bahasa itu terdiri atas unsur-unsur yang tersusun secara teratur (sistematis).Bahasa bukanlah sistem tunggal melainkan yang terdiri dari beberapa subsitem seperti, subsistem fonologi, gramatikal, dan leksikal.

Subsistem fonologi tidak hanya dapat ditelaah dari aspek linguistik mikro saja yaitu,telaah bahasa sebagai sistem leksikal bahasa. melainkan dapat pula dilakukan analisis berdasarkan aspek linguistik makro yaitu telaah bahasa sebagai sastra, linguistik makro secara umum bagaimana sistem bunyi yang digunakan dalam bahasa sastra, arti (meaning) dalam bahasa sastra, dan makna (signifikan) dibalik bahasa yang digunakan dalam sastra. Sehingga interpretasi makna karya sastra dapat dilihat dari berbagai paradigma, jika karya tersebut dilihat dari segi struktur maka kajiannya tentang struktur yang membangun sebuah karya sastra 
seperti diksi, penokohan, alur, dan latar.Jika dilihat dari segi semiotik maka bahasa merupakan sebuah tanda bermakna.

Terkait dengan bahasa sebagai tanda bermakna, maka karya sastra tersebut dapat pula ditelaah berdasarkan fonologi karena bagaimana sistem bunyi tersebut tersusun secara teratur dan sistematis sehingga dengan demikian dapat ditafsirkan arti dan makna yang terkandung dalam sebuah karya sastra tersebut.

Karya sastra puisi baik tradisional maupun modern mengandung berbagai macam makna yang perlu ditelaah secara mendalam.Salah satunyayaitu, kidung malat cowak.Menurut Suarka (2007:121) kidung merupakan tiruan bunyi ding dan dung atau nding dan ndung. Oleh karenanya kidung diikat oleh guru ding dan dung atau nding dan ndung,yakni pola pola nada akhir pada setiap baris atau larik dalam satu bait matra. Seperti contoh kidungkawitanwargasari, kidung ini guruding dan dung yang mengikat masingmasing baris antara bait satu dengan bait berikutnya selalu konsisten.Sesuai dengan definisi tersebut kidungmalatcowak juga diikat oleh guruding dan dung atau gurunding dan ndung. Akan tetapi, antara bait satu dengan bait berikutnya guru yang mengikat kidung malat cowak kurang konsisten.Kurangnya kosistensi guru dalam kidung malat cowak, mengakibatkan keragaman nada pembaca ketika menyanyikan kidung tersebut.

Konsistensi guru ding dan dung dalam kidung malat cowak dipengaruhi oleh latar belakang sosial pengarang. Pemilihan diksi dalam kidung tergantung dari seni berbahasa pengarang.Selain untuk menambah nilai estetika dari sebuah karya sastra kidung.Ragam bahasa sastra dalam kidung dipilih untuk menunjukan ragam wacana dan interpretasi makna sesuai dengan semangat jiwa zaman.

Kidung Malat Cowak sangat perlu untuk dikaji secara fonologi baik secara bunyi segmental penafsiran gabungan dari berberapa fonem dan suprasegmental meliputi, nada, tekanan, dan intonasi. Menurut Chaer (2009:120-123) bunyi segmental ialah bunyi yang dihasilkan oleh pernafasan, alat ucap, dan pita suara. Bunyi segmental ada empat macam yaitu, (1) Konsonan (bunyi yang terhambat oleh alat ucap), (2) Vokal (bunyi yang tidak terhambat oleh alat ucap, (3) Diftong dua vokal yang dibaca satu bunyi misalnya: /ai/ dalam sungai dan /au/ dalam kau, (4) Kluster (dua konsonan yang dibaca satu bunyi) misalnya: / ng/,/ny/, /tr/, /pr/. Selanjutnya supra segmental ialah bunyi yang berkaitan dengan keras lembut, panjang pendek, tinggi rendah dan jeda bunyi.Melalui analisis segmental dan supra segmental maka akan diketahui konsistensi intonasi dibalik makna dalam setiap baris kidung.

\section{Pembahasan}

\subsection{Analisis Bunyi Segmental Kidung Malat Cowak}

Selaning rahina wengi, galih kangkung tus ning bumbang, tampaking kuntul anglayang limasta umurug, pangisining sarwa lewih, pinge ulung rakta muang, tekuning ika dewa sakeng gunung, punika kresna apanuluhing apadang, abecik pukulun ratnaning rata.

Kutipan bait kidung malat cowak tersebut. Wacananya adalah tentang filsafat ketuhanan dibuktikan dengan beberapa bunyi segmental dan supra segmental yang akan dijelaskan sebagai berikut.

\section{Ciri 1 bunyikluster/iK/}

Pada bait tersebut di atas terdapat pengulangan bunyi kluster/iK/yang berarti /di/ contohnya /SelaniK/, /tusniK bumbaK/, /tampakiK/, /pangisiniK/,/ tekuniK/,/apanuluhiK/,/ratnaniK/ mengapa terjadi pengulangan bunyi tersebut karena selain untuk nilai estetika, bunyi/ing/merupakan gabungan vokal/i/ 
yang berarti suara merdu dan bunyi / $K /$ suara nyaring maknanya adalah fonem tersebut berfungsi untuk memperhalus ucapan karena ditujukan untuk memuji kebesaran tuhan

1. Kalimat selan/iK/ rahina wengi pada bait pertama berarti diantara siang malam atau antara ada dan tiada, antara sadar dan tidak sadar itulah kebenaran hakiki, menurut keyakinan hindu kebenaran hakiki yang dimaksud tiada lain adalah tuhan. Seperti disebutkan dalam bukunya Dharma Palguna,(2008:1) sama dengan kata pantaran/iK/Rwa yang berarti diantara yang dua, yaitu dualisme dikotomis [ $r w a$ bineddha], seperti baik-buruk, suci-leteh, surge-neraka. Seorang mahayogihidup bersama yang dua tapi tidak terikat oleh keduanya. Menurut keyakinan ajaran agama hindu orang terus berjuang membebaskan diri dari keduanya. Wrehaspati tattwa menyebutkan diantara surga dan neraka itulah tempat penyucian atma.

2. Kalimat Tusn/iK/ bumbang bunyi /ing/ tersebut juga mengacu pada fokus kata selaning tusning bumbang berarti seperti bambu yang dipotong sampai ke partikel terkecil.Secara makna demikianlah pengarang menggambarkan perwujudan tuhan sangat abstrak hingga lebih kecil dari atom namun tidak kecil. Seperti dalam slokaBhagawad Gita; avibhaktaA ca bhûtecu vibhaktam iva ca sthitam, bhûta-bhart[ ca taj jñeyaA grasicGu prabhavicGu ca. yang artinya Walaupun Beliau terbagi di antara insani, namun Beliau tidak dapat dibagi. Ia mantap sebagaiYang Maha Tunggal. Ia pemelihara segala makhluk, dan Beliau menciptakan sekaligus memusnahkan mereka.

3. Kalimat Tampak/iK/kuntul anglayang. Mengacu pada fokus kata selaning yang berarti pijakan kaki seekor burung putih berbulu halus yang terbang, jika mempergunakan indra maka seseorang tidak akan dapat menggambarkan bagaimana bentuk pijakan burung yang terbang sama halnya dengan tuhan itu sendiri susah untuk digambarkan.

4. Pangisin/iK/sarwa lewih.Artinya isi dari semua kebaikan.Bunyi / $i K /$ disini yang dimaksud adalah wujud tuhan sebagai isi dari segala kebaikan. Selain bunyi /iK/ tersebut terdapat pula pengulangan bunyi $/ w /$ merupakan semivokal (suara merdu) yaitu pada sarwa lewih sebenarnya lewih itu bersinonim dengan kata becik(bagus,indah dan baik) namun pengarang tidak menggunakan kata becik karena kata sebelumnya menggunakan kata sarwa agar terjadi pengulangan sehingga memiliki nilai estetika maka dipilihlah katalewih.

5. Tekun/iK/ ika dewa sakeng gunung. Artinya sungguh itu beliau dari gunung, bunyi $/ i K /$ yang dimaksud adalah tuhan. Menurut keyakinan orang bali bahwa benda tertinggi dapat dilihat menggunakan indra penglihatan yaitu gunung yang merupakan simbol dari tuhan.

6. Kresna apanuluh/iK/ apadang. Bunyi/ $i K /$ artinya krisna memberikan cahaya yang terang maknanya krisna sebagai manifestasi dari tuhan yang selalu memberikan pencerahan, sepertidalam sloka Bhagawad Gita ;jyoticâm api taj jyotis tamasah param ucyate, jñ̂naA jñeyaA jñ̂na-gamyaA $h$ [di sarvasya vicmhitam artinya beliau adalah sumber dari segala benda yang bercahaya. Beliau di luar kegelapan alam dan tidak terwujud.Ia adalah pengetahuan dan tujuan pengetahuan. Ia bersemayam di dalam hati sanubari segala makhluk.

7. Abecik pukulun ratna/niK/rata. Artinya benar-benar indah seperti seluruh permata.Bunyi /iK/ disini bagaimana tuhan tersebut sangat indah bagaikan seluruh permata. 
8. Selain pengulangan bunyi/ing/terdapat pengulangan bunyi $/ r /$ pada ratnaning dengan /r/ pada ratna. Mengapaterjadi pengulangan bunyi tersebut sebenarnya kata rata bersinonim dengan sami, hal tersebut dikarenakan dipengaruhi oleh bunyi kata sebelumnya yaitu ratna.

2.2 Analisis Bunyi Supra Segmental Kidung Malat Cowak

Menurut

Keterangan

: $\quad$ = bunyipendek $\because: \quad$ = bunyi panjang datar

$:::$ = bunyipanjang turun

$::::=$ bunyi panjang naik

- = nada naik

- = nadadatar

$\gamma=$ nadaturun

/ = jeda antar kata

// = jeda antar parafrase

\# $=$ jeda antar

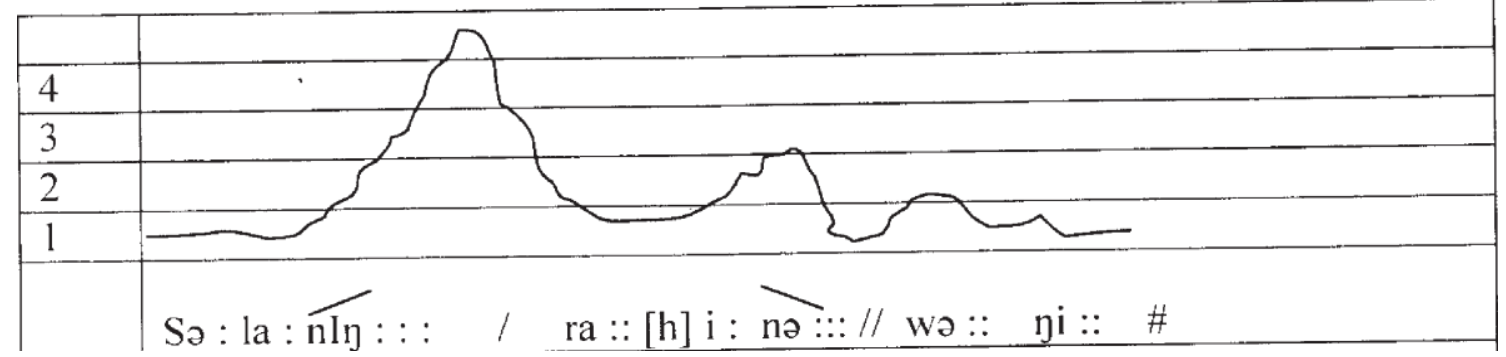

1. Nada, tekanan,intonasi

Selain bunyi merdu yang terdiri dari vokal /a,i,u,e,o/ yang mempengaruhi panjang pendeknya nada terdapat bunyi / ing/ letaknya tidak beraturan hal tersebut berpengaruh juga pada panjang pendeknya nada karena bunyi /ing/ dalam kidung itu menyatakan cara pujian tuhan jika kalimat tersebut dinyanyikan. Sistem tekanannya pun terjadi pada akhirkata $S Y$ : la : nIng dan intonasi akhir kalimat datar.

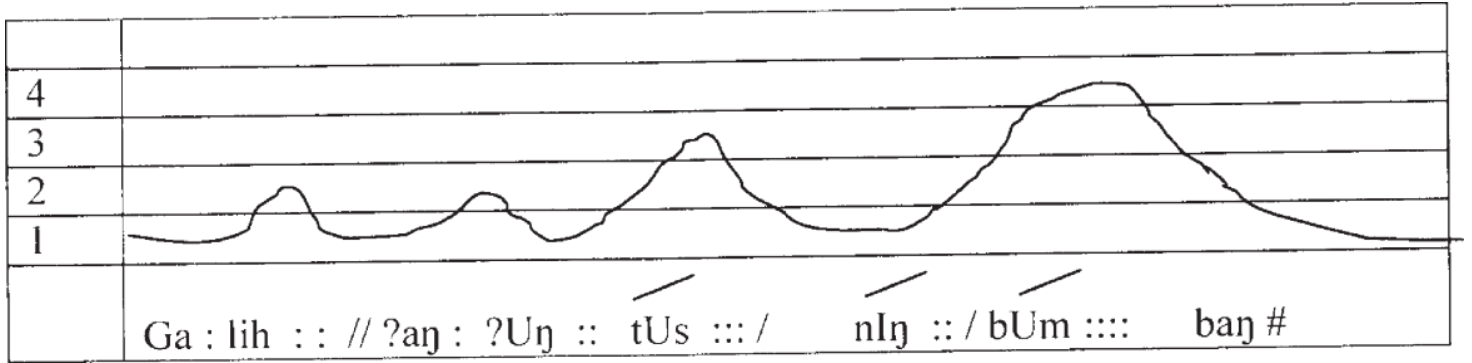

2. Nada, tekanan,intonasi

Nada naik terjadi pada kata $b U m$ bang hal tersebut karena dipengaruhi oleh nasal pada sebelum kata tersebut karena mengacu pada kosong (tuhan).Tekanan terjadi pada kata ?aK : ? UK, mengapa terdapat tekanan pada bunyi /?/ karena bunyi /?/ berkombinasi dengan bunyi nasal yang termasuk jenis euphomious (enak didengar), yang pelafalannya tidak mengalami hambatan atau nyaring, oleh sebab itu pengulangan bunyi tersebut menghasilkan suara melodius atau merdu. intonasi akhir kalimat datar. 


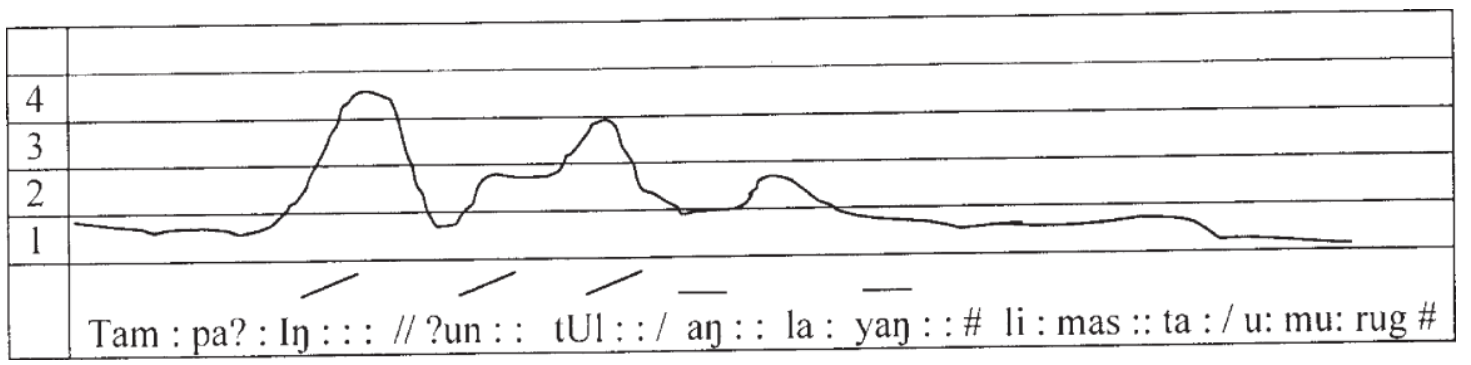

3. Nada, tekanan,intonasi

Nada naik terjadi pada kata Tampa?IK, ?untUl hal tersebut karena dipengaruhi oleh nasal $K$. Tekanan terjadi pada kata Tampa?IK ? untUl, mengapa terdapat tekanan pada bunyi /?/ karena bunyi/?/berkombinasi dengan bunyi nasal yang termasuk jenis euphomious (enak didengar), yang pelafalannya tidak mengalami hambatan atau nyaring, oleh sebab itu pengulangan bunyi tersebut menghasilkan suara melodius atau merdu. intonasi akhir kalimat datar.

\begin{tabular}{|c|c|}
\hline 4 & \\
\hline 3 & \\
\hline 2 & \\
\hline 1 & $\longrightarrow$ \\
\hline & 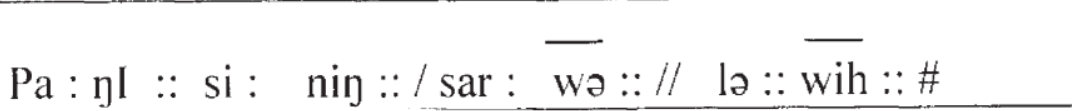 \\
\hline
\end{tabular}

4. Nada, tekanan,intonasi

Nada panjang datar terjadi pada kata sarwa dan lewih, hal tersebut karena dipengaruhi oleh nasal $\mathrm{K}$ sebelumnya. Tekanan terjadi pada kata tersebut juga, karena bunyi /w/merupakan semi vokal yang termasuk jenis euphomious (enak didengar), yang pelafalannya tidak mengalami hambatan atau nyaring, oleh sebab itu pengulangan bunyi tersebut menghasilkan suara melodius atau merdu.intonasi akhir kalimat datar.

\begin{tabular}{|l|l|}
\hline 4 & \\
\hline 3 & \\
\hline 2 & \\
\hline 1 & \\
\hline & Pi : ne $: / \mathrm{ul} \overline{\mathrm{Un}}:: / \mathrm{ra} ?$ ta $: / \mathrm{m} \overline{\mathrm{U}}::$ an \# \\
\hline
\end{tabular}


5. Nada, tekanan, intonasi

Nada panjang datar terjadi pada kata ulUK dan $m U a K$, hal tersebut karena dipengaruhi oleh nasal K. Tekanan terjadi pada kata tersebut juga, karena bunyi/u/ merupakan vokal yang termasuk suara merdu. intonasi akhir kalimat datar.

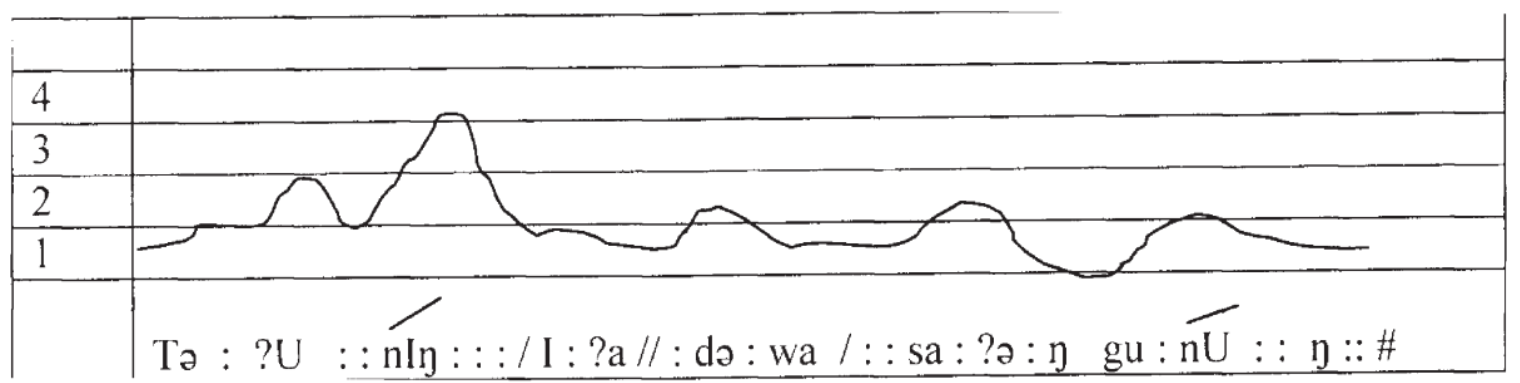

6. Nada, tekanan, intonasi

Nada panjang naik terjadi pada kata te? unK dan gunuK, hal tersebutkarena dipengaruhi oleh nasal $\mathrm{K}$ baik di awal kata maupun diakhir kata. Tekanan terjadi pada kata tersebut juga, karena bunyi /I/ dan / $\mathrm{U} /$ merupakan vokal yang termasuk suara merdu. intonasi akhir kalimat datar.

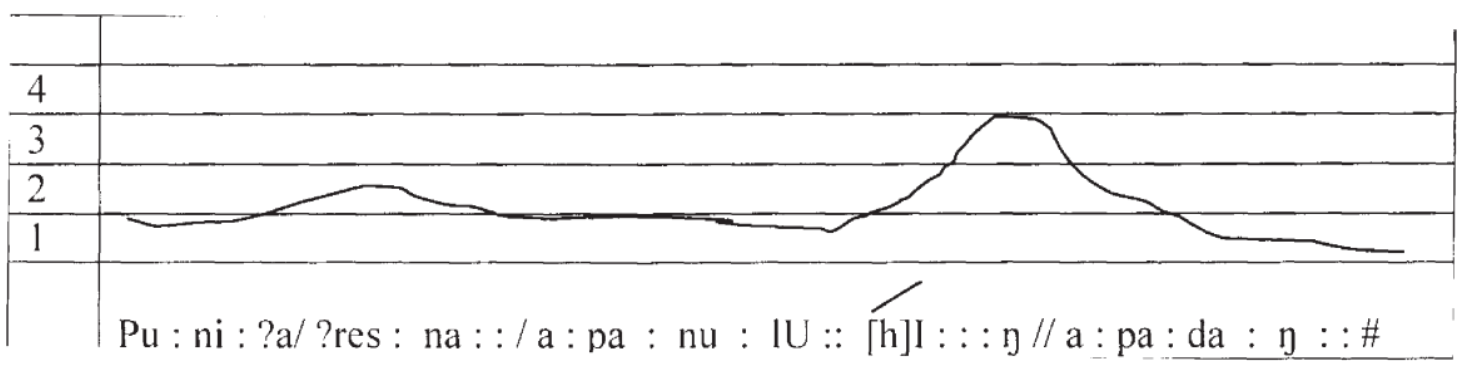

7. Nada, tekanan, intonasi

Nada panjang naik terjadi pada kata apanulU[h]IK, hal tersebut karena dipengaruhi oleh nasal $\mathrm{K}$. Tekanan terjadi pada kata tersebut juga, karena bunyi/I/ $\mathrm{dan} / \mathrm{U} /$ merupakan vokal yang termasuk suara merdu. intonasi akhir kalimat datar.

\begin{tabular}{|l|l|}
\hline 4 & \\
\hline 3 & \\
\hline 2 & \\
\hline 1 & a :be $:$ ci? / $\mathrm{Pu}: \mathrm{ku}: \mathrm{IUn}::$ / ratna nin: $:$ / ra $: \mathrm{ta} \#$ \\
\hline
\end{tabular}

8. Nada, tekanan, intonasi

Nada panjang naik terjadi pada kata ratnanIK, hal tersebut karena dipengaruhi oleh nasal K. Tekanan terjadi pada kata tersebut juga, karena bunyi /I/ bergabung dengan $\mathrm{K}$ merupakan vokal dan sengau yang termasuk suara merdu. intonasi akhir kalimatmenurun. 


\section{PENUTUP}

Karya sastra tradisional khususnya kidung di butuhkan berbagai macam metode dan teori untuk mengetahui interpretasi makna secara mendalam. Secara umum karya sastra dapat dianilisis menggunakan teori-teori sastra yang berkaitan dengan struktur yang membangun karya sastra tersebut.Akan tetapi perlu juga dilakukan analisis dari perspektif linguistik makro.Hal tersebut dikarenakan struktur terkecil dari sebuah karya adalah bahasa.Selain itu melalui analisis sistem bunyi karya sastra kidung dapat diketahui konsistensi intonasi dibalik makna bahasa yang terkandung. 


\section{Daftar pustaka}

Chaer, Abdul. 2009. Fonologi Bahasa Indonesia. Jakarta: Rineka Cipta.

Verhaar, J.W.M. 2012. Asas-Asas Linguistik Umum. Yogyakarta: Gadjah Mada University Press

Siswantoro. 2010. Metode Penelitian Sastra Analisis Struktur Puisi. Yogyakarta: Pustaka Pelajar.

Suarka, I Nyoman. 2007. Kidung Tantri Pisacarana. Denpasar: Pustaka Larasan.

\section{. Kidung Malat Cowak.}

Padangbulia

, Buleleng, Singaraja 